\title{
The Review
}

\section{Working in a primary care based antiretroviral team in KwaZulu-Natal, South Africa}

\section{WHAT IS THE PRIMARY CARE ANTIRETROVIRAL TEAM?}

The antiretroviral (ARV) team is designed to support isolated rural primary care clinics in administering the South African National HIV and AIDS and TB Programme. Its remit is to move HIV treatment from hospital into the South African primary care system. I have been working as the 'roving doctor' in this team and have had the pleasure to rove alongside my ever-smiling and unruffled nurse mentor, Busie, and our most talented driver Mkhaliphi. Mkhaliphi is so adept at avoiding potholes on dirt track roads, that he applies the same strategies to avoiding speed humps on more conventional roads.

Together we traversed the province, reaching remote rural clinics, where lone nursing sisters struggled to cope with the demand. You may feel busy and overworked in your NHS job but I want you to picture the following: a clinic many miles from any town, where the waiting room is so stacked with people it spills outdoors, under the sun, with people standing stoically in a twisting conga line of need. If you nip outside to go to the toilet all eyes follow you, a collective moan goes up from the patients as they think you are leaving!

\section{WHY IS THE ARV TEAM NEEDED?}

The medical context

HIV is a global epidemic and unlike flu, it's a chronic disease. In South Africa the overall prevalence rate is around $18 \%$ of the whole population. ${ }^{1}$ If we zoom in to focus on women between 15-49 years (those of child-bearing age), the prevalence is estimated at $29.4 \%$. If we look at the province of KwaZulu-Natal, things get even worse with $39.5 \%$ prevalence in this group. ${ }^{2}$ This represents a challenging burden of disease in a developing country and contrasts sharply with $0.2 \%$ prevalence in the UK. ${ }^{1}$ HIV is the root cause of the majority of primary care presentations.

\section{Why does HIV treatment need to be administered in primary care?}

KwaZulu-Natal is a large province, roughly the same size as Portugal. It is reflective of the social landscape, which exists in South Africa as a whole. The population is inexorably drawn to cities where there are more facilities and work, but people's homes remain in rural areas. This is a phenomenon that is seen the world over but is entrenched in South African society due to the legacy of apartheid.

During the apartheid years, rural areas were made into black 'homelands' and given limited autonomy by the government. The inhabitants of the homelands were stripped of South African citizenship. The majority of the good agricultural land and large cities remained inside white South Africa, thus keeping economic activity under government control. The 'homelands' had little infrastructure, people who had been shifted there found that they had to find a job in South Africa far away from their family.

Although the homelands have been abolished, most people in KwaZulu-Natal originating from rural areas find themselves displaced to cities or towns during the working week. This is considered normal. As a way of life it fundamentally changes the fabric of communities, separating partners, parents, and children. Arguably it increases the prevalence of multiple concurrent relationships, a major driver of HIV. It also perpetuates the lack of facilities in rural areas, as they become a weekend version of dormitory towns. However, when people are too sick to work, they return home to their family.

All of the rural clinics I served were located far from the tarmac roads; they clung to the side of green mountains or were tucked in the middle of pine plantations. They provide the rural poor access to health care, but are still difficult to get to. People have to walk many kilometres, or bump along on dirt track

\section{A rondavel in the Drakensburg, KwaZula-Natal.}

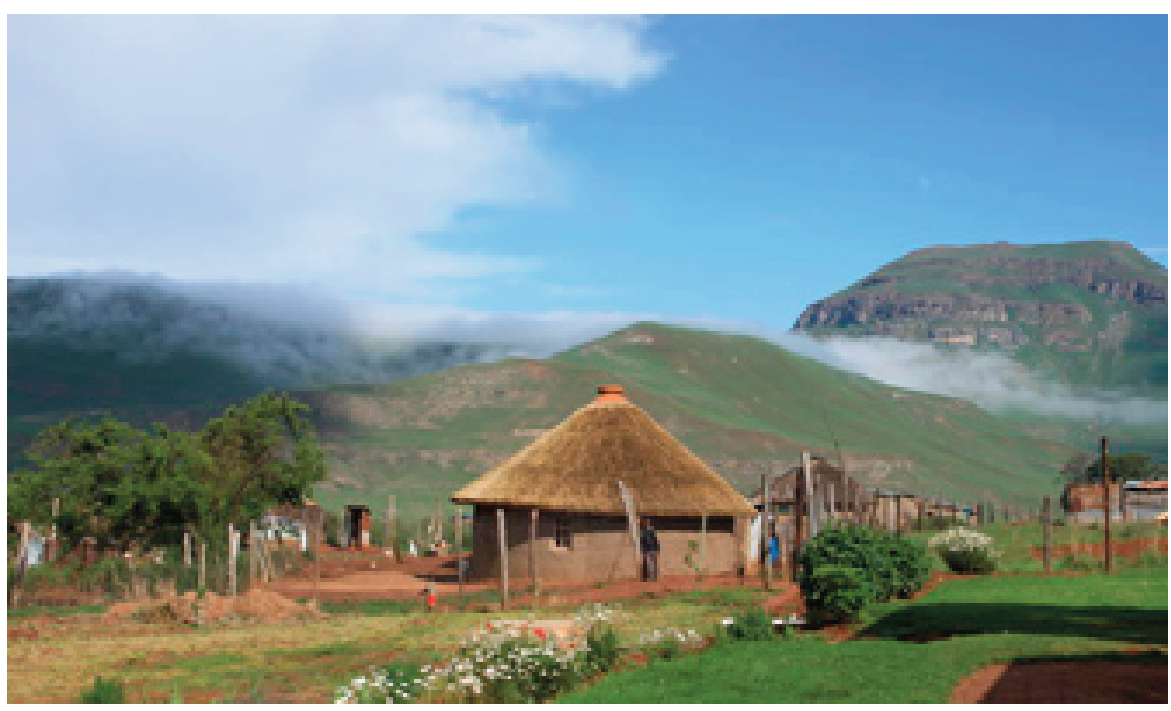

roads in the back of a 'bakkie' (truck) or come on horseback. This unconventional means of transport engendered a feeling of being in a spaghetti Western. When I glanced outside my clinic window, tethered horses grazed, swishing their tails, while their owners sat in a line outside my door. On a more serious note, the lack of a patient transport system makes it hard for the sickest patients to access the clinic. They are often the last to arrive, crawling in near the close of the day.

These transport issues make it difficult if not impossible in some circumstances for patients to reach tertiary care. Starting drug treatment for HIV and maintaining treatment requires repeated and regular attendance. Getting to the local hospital often requires a day of travel on dirt track roads. This can be not only physically difficult but also prohibitively expensive, despite the actual care being free. For example, to commence HIV treatment you have to visit two or three times and then continue to visit monthly. If you are a family of four living on a government pension of $£ 100$ a month, such trips can easily eat up half of your total monthly income. So, the hope is, that bringing treatment as close to the patient as possible will improve take-up and adherence rates and thereby reduce morbidity and mortality.

\section{The social and physical context}

I travelled to the clinic along potholed roads, past rondavels, which are round thatched huts painted a striking fuchsia or primrose 
yellow. They clash madly with the muted green and muddy hues of the surrounding mountains. Women carrying huge bundles of firewood casually glance behind and move aside for the car to hurtle pass. Children and people wave as we leave them in a dust cloud.

The areas I served are located in the richest country in Africa, but there is often no electricity, running water, shops, or commercial industry. Heat and cooking are done on a central fire pit, smoke rising through the open ceramic chimney within the thatch, the mud walls rarely have windows. These two factors serve to thicken the air to a glutinous quality, making housevisits a paroxysm of coughing. Chronic obstructive pulmonary disease is common in women who cook over these fires; smoke-damaged cilia and the dark atmosphere also contribute to the development of tuberculosis (TB). Water is of variable quality and is collected from a village water point; water-borne disease is therefore common.

This glaring lack of utilities undoubtedly affects health. There is fledgling investment in these areas; for example, new schools, clinics, and roads. Social health interventions are appearing too, such as supporting child health surveillance, and attempts to provide food for those with malnutrition.

\section{Communication issues}

The rural patients I saw largely do not speak English but conversed in Zulu. This contrasts sharply with black South Africans living in cities. They often find it difficult to meet my eye and seem a little scared but are quick to laugh at my mispronunciations. I was enabled to overcome the language barrier by the skills of a nurse or healthcare worker translator. This was a great way to exchange medical and cultural knowledge as well as to communicate with patients.

\section{THE ARV DRUG PROGRAMME}

The National HIV and Aids and TB Programme stuttered into action in 2004. In April 2010, the threshold for treatment was lowered; pregnant women and those with TB and a CD4 count of 350 or those diagnosed as having World Health Organization Clinical Stage 3 HIV could be treated. At the same time, the ARV pharmacopoeia was extended to include a greater number of less toxic drugs.

There's debate around these treatment criteria. It could be argued that the treatment threshold is still too strict, allowing the immune system to decline until

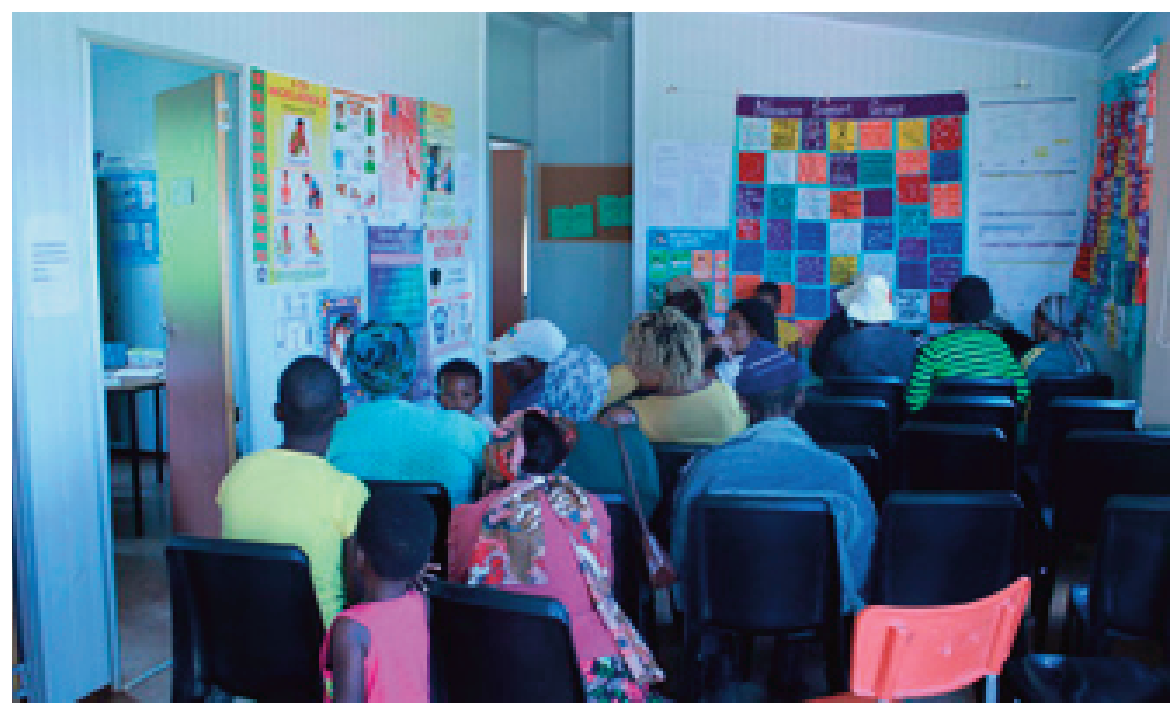

\section{A clinic waiting room at the end of the day.}

many are susceptible to TB and then become entitled to treatment. To counter this argument, the Department of Health would point to the prophylaxis programme, which provides co-trimoxazole and isoniazid, to HIV positive individuals not eligible for treatment. The idea is to prevent opportunistic infection in those at risk, but it remains to be seen how effective this approach will be. The strategy rests on people testing early and appropriate prescribing of isoniazid. People have a tendency to test when they are sick and have often missed the window of opportunity to receive prophylaxis. Overzealous prophylaxis prescribing in the presence of such a high TB prevalence can lead to patients who have TB being given prophylaxis rather than treatment.

The treatment criteria are a compromise between economic constraints and providing free care accessible to those who need it most - these are decisions that all public healthcare systems have to make. The fact remains, many more people are now entitled to treatment than before April 2010.

\section{The administration of the programme}

The ARV programme is delivered through hospital and primary healthcare clinics. Clinics provide many of the same services as UK general practice. They manage chronic disease, provide antenatal care, family planning, vaccinations, and make onward referrals to hospital. They have an additional role in the diagnosis of TB and HIV and the distribution of appropriate treatment. All treatment is free at the point of access and largely provided by nurses.

Everyone attending the primary healthcare clinics should be offered near patient HIV testing and pretest counselling. The test takes around 5 minutes to produce a result. If positive, a further confirmatory test is done. A positive test means the patient's CD4 count is taken and prophylaxis offered. When the patient returns, they are clinically staged if their presentation is within the treatment threshold, baseline bloods are taken, and they are referred to 'literacy' classes. The literacy classes cover the nature of HIV, transmission, treatment, disclosure, and the possible side effects of the drugs. These classes are essential to combat a poor level of education and the complex nature of treatment.

Until recently, ARV and TB treatment have primarily been doctor led. However, due to increasing demand and a doctor shortage, nurses are being trained to administer all aspects of the HIV programme. Nurses, who are community based, have often watched while their patients get sicker and die as they are unable to access physician based care. So although the ARV drug administration is a considerable workload and responsibility, it does come as a relief to many nurses.

\section{The work}

My remit was firstly to assess patients and to commence treatment for TB and HIV, to monitor the progress of patients already on treatment, detect adverse drug events, pick up the emergence of viral resistance, and provide alternative treatment. The second important part of the job was to train the nurses to do all these tasks safely.

\section{The patients}

The majority of patients I saw attending the clinic were in their mid-20s, in what should be the prime of their lives. This represents 


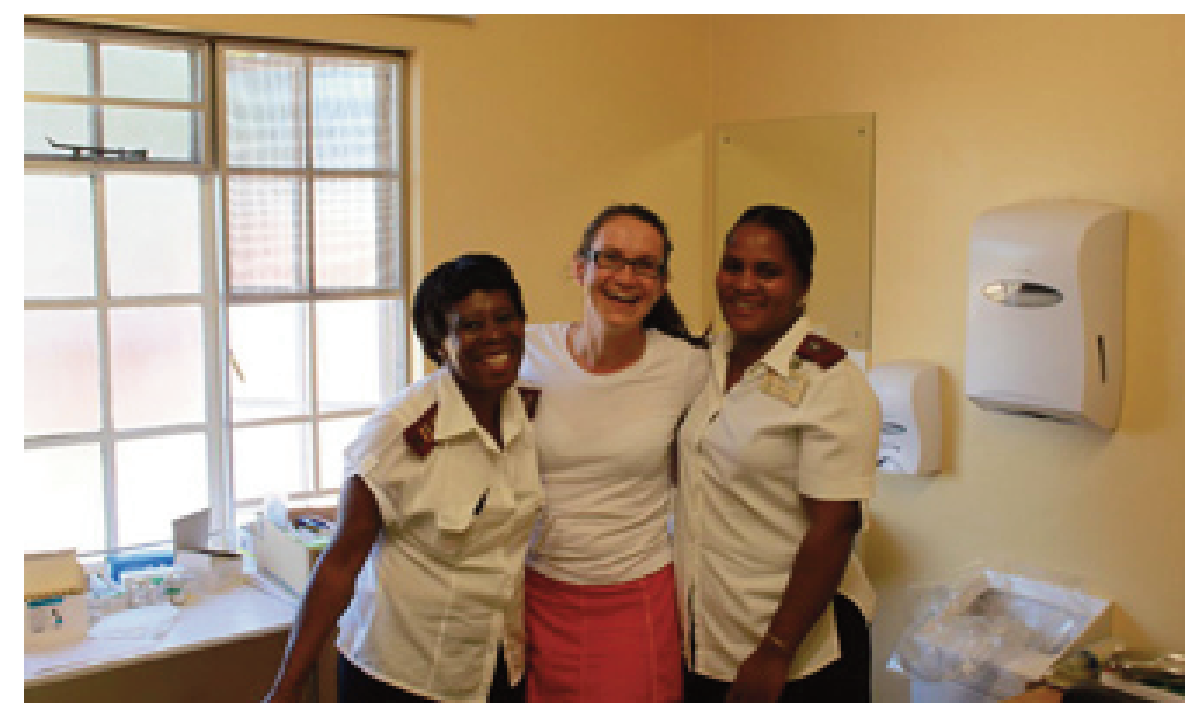

The fabulous sisters, Sister Hadebe and Sister Thobela, from Gqumeni clinic.

the natural history of the disease, from infection at sexual debut to AIDS-defining condition; it is typically a journey of between 6 and 9 years depending on comorbidity. There were exceptions to this: a heartbreaking example would be a fragile 17year-old female I met. Needing a stick to stand, she hobbled into my consulting room, ravaged by her co-infection of TB and HIV. Lifting her onto the bed was like lifting a 5-year old. As part of her treatment I was encouraging her to take up the offer of contraception and she blankly told me she had never had sex; she was Makoti, a virgin. I looked at her quizzically, wondering if vertical transmission could present so late. The all-knowing nurse working with me intervened, he knew this family. According to him they were all infected - from the toddler to the 83-year-old 'gogo' lgrandmother) - 12 members in all. We asked the girl some more questions and the following story emerged. Around 5 years ago her older brother had become very ill, and the family called a 'sangoma' la witch doctor), at this point in time it would have been difficult for them to access conventional HIV care. He cut her brother, to release the bad 'muti (black magic) that was ailing him. Then, with the same razor, he cut the chest wall of all the other family members. This was to provide an outlet for the muti, so that as it was exorcised from her brother it would not be able to infect other family members. In doing so, it seems he succeeded in infecting that entire family with HIV.

Patients would often present in extremis. People sustain and survive a level of sickness which I have rarely seen in the UK. Biologically speaking, most of my patients had young hearts, lungs, and kidneys,

The list could be endless, but given the is spread more thinly. right treatment these young people who present in such extremis do incredibly well. The drugs to treat AIDS-defining conditions are generally available in South Africa within the public system. The knowledge to recognise and treat them is spread more thinly.

\section{The problems}

A colleague once said to me that South Africa has first world aspirations and third world infrastructure. This can mean that health programmes, although laudable, do not always succeed. An example which illustrates this is my experience of South African cervical screening. When I arrived I was heavily encouraged to undertake cervical screening as part of a district health campaign. Cervical screening does have a huge potential to improve health outcomes in HIV-positive women. This is evidenced by a large trial in Zambia which showed that by screening 32 women and providing appropriate treatment, it was possible to prevent one death from cervical cancer. ${ }^{3}$ So, convinced by the numbers needed to screen' I went to work. I was a merry smear crusader, waving my speculum at a surprisingly enthusiastic audience. However, when the smear results came back, what proved difficult was to get women booked in for prompt colposcopy. The waiting list was closed as they did not have 'next year's diary', and when you could get someone in, it was in 6 months' time. 'What's the point of screening?' I raged, 'If I cannot do anything about the results?.

There had been no planned increase in the colposcopy service in the district to cope with the deluge of abnormal smears that the campaign generated. So the women who now knew they had highgrade lesions nervously waited and looked imploringly at me.

After we have strongly 'motivated' la phrase I have learned in South Africa), and senior hospital doctors from the tertiary hospitals got involved (thank you Dr Titus!), an increased colposcopy service does indeed look likely. However, this whole situation made me acutely aware that the service provided is only as good as the

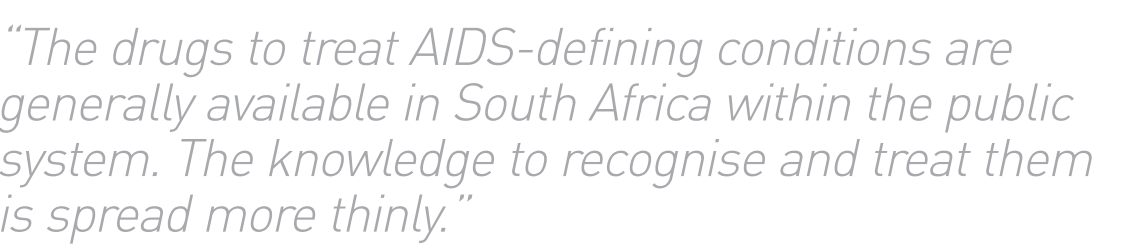

"The drugs to treat AIDS-defining conditions are generally available in South Africa within the public system. The knowledge to recognise and treat them 
weakest point in the chain; there is no point in screening if you cannot provide treatment for the problems you find.

A second problem is people often wait until they are very sick to test for HIV. This drastically affects their long-term prognosis. You can get them better from their acute sickness but their life expectancy is adversely affected. It seems this is slowly changing, but it dates from the time when there was no treatment to be had. An HIV-positive result was a death sentence you could do nothing about, so why would you test? This is no longer the case, but every family in KwaZulu-Natal will have a member who has died from untreated AIDS. The memory of these deaths instils a fear, which determines the actions of today.

A third problem is the massive skill shortage in South Africa. Although the country trains a large number of doctors per year, after their mandatory community service years $25 \%$ migrate to greener pastures overseas. The net effect is that the number of doctors in the country is declining from just over 27000 today to just over 23000 predicted for 2020 . This means at a time of one of the greatest challenges for health in South Africa there are just 55 doctors for every 10000 patients compared to 230 to 10000 in the UK. ${ }^{4}$ These doctors are not evenly spread throughout the country, with most choosing to work in cities, and the small number who do work rurally often practice privately: the pay and the workload are much better. There is no blame in seeking a better life, but the brain drain is seriously impeding the delivery of health care. The post I filled had been advertised three times in the preceding year without applicants.

\section{WHAT TOOK ME TO SOUTH AFRICA? WHAT PREPARATION DID I DO?}

I am a UK-trained GP and have been working for the last 5 years in Edinburgh. I first undertook a short 6-week sabbatical, working alongside a doctor who had considerable HIV experience. I later returned for a longer period. Both placements were organised through Africa Health Placements, who also organised a 3-day course on HIV and TB medicine, which was invaluable and certainly one of the best clinical courses I have ever attended. I also read a lot before I went and when I was there. The books I found useful are listed opposite.

The other big resource I was privy to was the extremely experienced HIV and TB clinicians in situ in various positions throughout KwaZulu-Natal. They were incredibly helpful when faced with my queries or discussing the best options for particularly difficult clinical scenarios over the phone. I also shared accommodation with fellow volunteer doctors. This did mean evenings sometimes degenerated into $X$ ray meetings and case presentations, as we all sought mutual reassurance and opinions. A ban on medical discussions after $8 \mathrm{pm}$ and at weekends was quickly instituted to popular acclaim, not least from my non-medical partner.

I worked as a volunteer, which allowed me flexibility and the opportunity to drag my partner along; paid positions are possible for those committing for at least a year.

\section{DID I ENJOY IT?}

Every day that I worked I felt I made a tangible difference to people's lives; my excitement and engagement with medicine was completely renewed. In a place where there is so much clinical need, it is easy to help.

\section{THE FRINGE BENEFITS}

South Africa is a beautiful country. I lived in the Southern Drakensberg and the view from my veranda looked up towards the towering peaks of Sani Pass, which leads into Lesotho. It's magnificent to hike in, with more reliable weather than Scotland.

I have learned a huge amount about HIV and TB treatment and will continue to pursue this as a special interest within my primary care work.

\section{THE REAL HEROES}

These are the people who make it their life's work, both those born in South Africa and those who adopt it as their homeland. I would like to dedicate this essay to them.

\section{Jean Beckley,}

Sessional GP currently on maternity leave.

\section{Provenance}

Freely submitted; not externally peer reviewed.

\section{Are you interested?}

Edzimkulu. A Society for Children with AIDS: http://www.edzimkulu.org/

Africa Health Placements: http://www.ahp.org.za/

\section{Further reading}

Wilson D, Cotton M, Bekker L-G, et al. Handbook of HIV medicine. Cape Town: Oxford Southern Africa, 2009.

Heller T (ed.). Hlabsia case book in TB and HIV medicine. KwaZulu Natal: Africa Centre for Health and Population Studies, 2009.

\section{ADDRESS FOR CORRESPONDENCE}

\section{Jean Beckley}

C/O Jackie O'Connor, Practice Manager,

Craigmillar Medical Group, 106 Niddrie Mains Road, Edinburgh, Midlothian EH16 4DT, UK.

E-mail: jean.Beckleyðyahoo.co.uk

Foundation for Professional Development. The integrated management of TB, HIV \& STI in the primary health care setting. Lynnwood Ridge: Foundation for Professional Development, 2010. http://www.foundation.co.za laccessed 1 Dec 2011).

University of Cape Town Lung Institute. PALSA Plus. http://www.knowledgetranslation.co.za/content/prog rammes_palsa.html laccessed 1 Dec 2011).

DOI: 10.3399/bjgp12X616391

\section{REFERENCES}

1. NAM. E-atlas. http://uww.aidsmap.com/eatlas//Sub-SaharanAfrica/cat/1698/page/1374740/ laccessed 21 Nov 2011).

2. Department of Health. National antenatal sentinel HIV and syphilis prevalence survey in South Africa, 2009. Pretoria: Department of Health, 2010.

3. Alcorn K, Safreed-Harmon K. Preventing cervical cancer: good outcomes from screening programme for HIV-positive Zambian women. London: NAM. http://www.aidsmap.com/Preventing-cervicalcancer-good-outcomes-from-screeningprogramme-for-HIV-positive-Zambianwomen/page/1437730/ laccessed 21 Nov 2011)

4. Watson $\mathrm{L}$. Sharp decline in doctors expected. http://www.fin24.com/Economy/SouthAfrica/Sharp-decline-in-doctors-expected20101122 (accessed 21 Nov 2011). 